Stefan Schröder

Freigeistige Organisationen in Deutschland 


\section{Religion and Its Others}

Studies in Religion, Nonreligion and Secularity

Edited by

Stacey Gutkowski, Lois Lee, and Johannes Quack

\section{Volume 8}




\section{Stefan Schröder Freigeistige Organisationen in Deutschland}

Weltanschauliche Entwicklungen und strategische Spannungen nach der humanistischen Wende

\section{DE GRUYTER}


ISBN 978-3-11-061148-9

e-ISBN (PDF) 978-3-11-061283-7

e-ISBN (EPUB) 978-3-11-061162-5

ISSN 2330-6262

\section{Library of Congress Cataloging-in-Publication Data}

Names: Schroder, Stefan, 1975- author.

Title: Freigeistige Organisationen in Deutschland : Weltanschauliche

Entwicklungen und strategische Spannungen nach der humanistischen Wende /

Stefan Schroeder.

Description: 1 [edition]. | Boston : De Gruyter, 2018. | Series: Religion and

its others; Volume 8 | Includes bibliographical references and index.

Identifiers: LCCN 2018029289 (print) | LCCN 2018038063 (ebook) | ISBN

9783110612837 (electronic Portable Document Format (pdf) | ISBN

9783110611489 (print : alk. paper) | ISBN 9783110611625 (e-book epub) |

ISBN 9783110612837 (e-book pdf)

Subjects: LCSH: Secular humanism--Germany. | Free thought--Germany.

Classification: LCC BL2765.G3 (ebook) | LCC BL2765.G3 S37 2018 (print) | DDC

211/.60943--dc23

LC record available at https://lccn.loc.gov/2018029289

\section{Bibliografische Information der Deutschen Nationalbibliothek}

Die Deutsche Nationalbibliothek verzeichnet diese Publikation in der Deutschen

Nationalbibliografie; detaillierte bibliografische Daten sind im Internet über http://dnb.dnb.de abrufbar.

(C) 2018 Walter de Gruyter GmbH, Berlin/Boston

Druck und Bindung: $\mathrm{CPI}$ books $\mathrm{GmbH}$, Leck

www.degruyter.com 